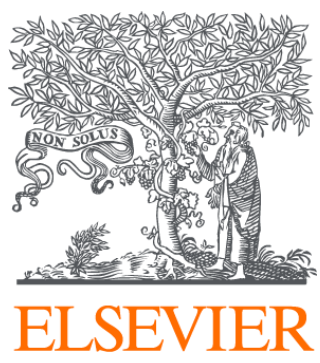

Since January 2020 Elsevier has created a COVID-19 resource centre with free information in English and Mandarin on the novel coronavirus COVID-

19. The COVID-19 resource centre is hosted on Elsevier Connect, the company's public news and information website.

Elsevier hereby grants permission to make all its COVID-19-related research that is available on the COVID-19 resource centre - including this research content - immediately available in PubMed Central and other publicly funded repositories, such as the WHO COVID database with rights for unrestricted research re-use and analyses in any form or by any means with acknowledgement of the original source. These permissions are granted for free by Elsevier for as long as the COVID-19 resource centre remains active. 
Research Paper

\title{
Parenting under pressure: A mixed-methods investigation of the impact of COVID-19 on family life
}

\author{
Kristen A. Chu ${ }^{a}$, Chloe Schwartz ${ }^{\text {a }}$, Emily Towner ${ }^{\mathrm{d}}$, Nadine A. Kasparian ${ }^{\mathrm{b}, \mathrm{c}}$, Bridget Callaghan ${ }^{\mathrm{a}, *}$ \\ ${ }^{a}$ Department of Psychology, University of California, Los Angeles, CA, USA \\ ${ }^{\mathrm{b}}$ Cincinnati Children's Center for Heart Disease and Mental Health, Heart Institute and Division of Behavioral Medicine \& Clinical Psychology, Cincinnati Children's \\ Hospital, Cincinnati, OH, USA \\ ${ }^{\mathrm{c}}$ Department of Pediatrics, University of Cincinnati College of Medicine, Cincinnati, OH, USA \\ ${ }^{\mathrm{d}}$ University of Cambridge
}

\section{A R T I C L E I N F O}

\section{Keywords:}

COVID-19

Pandemic

Parent

Child

Qualitative

Mixed-methods

\begin{abstract}
A B S T R A C T
Background: development and implementation of effective family-based psychosocial intervention and treatment strategies during COVID-19 will require a detailed understanding of how the virus has impacted the lives of families.

Methods: written reports on the life impacts of COVID-19 for parents $(n=56)$ and their children $(n=43)$, and a questionnaire assessing parent positive and negative affect, were collected between April and May 2020. An inductive approach was used to identify themes in written reports, followed by statistical analysis to explore associations between themes and changes in parent positive and negative affect pre- and post-writing.

Results: parents and children reported both positive and negative psychosocial impacts of the virus, though parents expressed a greater diversity of positive themes than children. Common themes reported by parents included concerns about the impact of COVID-19 on their children, health concerns for others, and the stressful balancing act of parenting, assisting with children's school work, and working from home. Many parents reported gratitude, and reflected on the upsides of the pandemic for family relationships and parent-child bonding. Parents who expressed gratitude reported a decrease in negative affect pre- to post-writing. Common child-reported themes included yearning to return to school, pandemic-related fears, and longing for social connection.

Limitations: the sample included a cross-section of mostly White (non-Hispanic), dual income, well-educated mothers, primarily from the United States.

Conclusions: both parents and children reported reduced wellbeing during the COVID-19 pandemic. Future research should focus on identifying how to fulfill children's social needs and lessen caregivers' burdens during this time.
\end{abstract}

\section{Introduction}

The SARS-CoV-2 (COVID-19) pandemic has had a tremendous global impact, with over 55 million confirmed cases worldwide (World Health Organization 2020). Due to widespread stay-at-home and social distancing mandates to prevent the spread of the virus, the psychosocial toll of this disease (including effects on mental health, academic achievement, employment, and social functioning), and the indirect morbidity and mortality associated with these effects, are likely to far outnumber infection rates (Luo et al., 2020). Moreover, due to the complex interactional and developmental nature of these effects, the magnitude of the psychosocial sequelae associated with COVID-19 may not be comprehended for years into the future (Prime et al., 2020).
While children and young people are at lower risk of contracting the novel coronavirus, and from associated health complications, they may be at heightened risk of adverse psychosocial outcomes (Golberstein et al., 2020). School closures paired with restrictions on children's social activities may have unique impacts on young people, occurring at a particularly plastic stage of brain and socioemotional development. In preliminary studies, children have reported elevated academic difficulties as a result of online schooling during COVID-19 (Bhamani et al., 2020), with those who are economically disadvantaged being at greatest risk (Van Lancker and Parolin, 2020). There is also evidence for an increase in anxiety and depressive symptoms in children and adolescents during COVID-19 (Duan et al., 2020; Saurabh and Ranjan, 2020; Racine et al., 2020), Bobo et al. (2020) supporting the notion that this pandemic is a significant source of psychosocial adversity for youth.

\footnotetext{
* Corresponding author.

E-mail address: bcallaghan@ucla.edu (B. Callaghan).
} 
Parents serve an important emotion regulation (i.e., buffering) role for their children (Gunnar and Hostinar, 2015). As such, parental mental health is critically important for healthy child and family functioning, especially during adversity (Prime et al., 2020). However, parents too are at increased risk for psychosocial burdens during the pandemic due to the strain associated with working and parenting from home, caring for elderly family members, homeschooling their children, or assisting their online schooled children with their academic responsibilities (Cluver et al., 2020). Many households have also experienced changes in income and employment (Jenco, 2020), and restrictions on social movement can affect parents' access to social connection and instrumental support (Cameron et al., 2020). Several studies report increases in parenting stress during COVID-19 (Cameron et al., 2020), as well as clinically-elevated levels of maternal anxiety and depression (Thapa et al., 2020). Increases in parenting stress and decrements in parent mental health can lead to harsh parenting practices and greater potential for child abuse, neglect or exposure to family violence (Brown et al., 2020), further highlighting the important role of parents as gatekeepers to child wellbeing. Nonetheless, despite the proliferation of risk factors parents face during the pandemic, some families have reported positive psychosocial consequences, such as improvements in the marital relationship (Günther-Bel et al., 2020). The wide range of potential responses to this global event underscores the need for detailed exploration of the meaning this experience holds for families.

Qualitative research is an important means of gaining detailed information, and is particularly useful during the early phases of the pandemic, when the meaning of this experience continues to be explored. Moreover, as written disclosure about traumatic or emotional experiences can affect an individual's emotional reactivity, potentially through the operation of regulatory emotional processes (Pennebaker, 1997; Murray and Segal, 1994; Pennebaker and Francis, 1996), it is possible that engaging in written qualitative research with families during the pandemic may have (at least a short-term) positive effect on mood. Indeed, studies have shown that individuals who express gratitude in their writing exhibit increases in their positive affect and wellbeing (Toepfer and Walker, 2009), as well as decreased depressive symptoms (Booker and Dunsmore, 2017).

In the current study we collected written reports from parents and children about the impacts of COVID-19 on their lives and analyzed those written narratives for consistent themes and patterns. We also explored the associations between parent engagement in gratitude during writing and changes in parent positive and negative affect pre- and postwriting.

\section{Methods}

\subsection{Participants}

Between April and July 2020, an anonymous online survey was completed by 324 parents aged 18 years or above, with at least one child aged between 6 and 17 years. From April to May 2020 there was a written response option at the end of the survey which any parents and children could complete if they desired. The sample who completed the written response portion was $n=56$ parents and $n=51$ children (Table 1). From this sample, we excluded 8 child responses where it was clear that the parent wrote the response for the child (e.g., "my child thinks that ..."), resulting in a final sample of $n=43$ children. There were no geographical restrictions on study participation, though parents had to read and write in English. Participants opted into a draw to win one of twenty $\$ 100$ gift cards and winners were selected at random from the full sample at the end of the survey (i.e., in July 2020). Parents completed quantitative measures first, followed by their own written report, before the child wrote their own report. The study protocol was approved by the Institutional Review Board at the University of California, Los Angeles.

\subsection{Measures}

Writing Prompt. Parents and children were asked to write about their 'deepest thoughts and feelings about COVID-19' for five minutes each. The prompt was altered from past research which used writing as a therapeutic activity 23 .

Positive and Negative Affect Scale (PANAS) (Watson et al., 1988). Parents reported their positive and negative affect immediately before and after completing their written report. Internal consistency was high (prepositive affect $\alpha=.89$, post-positive $\alpha=.89$, pre-negative $\alpha=.87$, postnegative $\alpha=.88$ ).

\subsection{Analyses}

Written Reports: We employed a bottom-up inductive approach, with some theoretical expectations based upon recent findings during the COVID-19 pandemic; we expected reports of fear of COVID-19 (Saurabh and Ranjan, 2020) and parenting stress (Cameron et al., 2020; Whittle et al., 2020), as well as positive reflections, especially gratitude (Sun et al., 2020). Parent responses were analyzed while blind to child responses. The qualitative analysis process and hypotheses were preregistered; https://osf.io/pc46e/, and are described in short here. An iterative, six-phase thematic analysis process was performed to assess the emotional content and identify themes embedded within parents' and children's written qualitative responses (Braun and Clarke, 2006). The process involved the collaboration of two researchers (KC and $\mathrm{BC}$ ) and was based on multiple conversations to reach agreements. As such, there was no assessment of interrater agreement as all coding was collaborative. Phase 1 involved data familiarization and initial annotation by two researchers (KC, BC). In Phase 2, the two researchers discussed their annotations and summarized the sentences into smaller chunks (called codes). In Phase 3, the researchers clustered those codes into overarching themes by grouping together codes based on higher order concepts. Once broad, higher-order themes were agreed upon by both researchers, one researcher $(\mathrm{KC})$ made another pass through the data to place all the coded extracts into the most representative theme/s (codes could fall under multiple themes). In Phase 4, both researchers reviewed the themes to ensure each was discrete, merged themes that were largely overlapping, and once more ensured that the coded extracts were adequately represented by the higher-order theme. Once agreement on the final themes was reached, the researchers worked together to define the content of the themes (Phase 5), before writing about them in the manuscript (Phase 6).

Effect of Writing on Parent Affect. As we had a theoretical expectation based on past research (Sun et al., 2020) that many parents would express gratitude in their writing, and due to the preexisting literature on the effects of gratitude journaling on affect (Toepfer and Walker, 2009; Booker and Dunsmore, 2017), we tested whether reflecting on the theme of gratitude in written responses (binary coded 0 to indicate no citation of the theme and 1 to indicate citation of the theme) would lead to increases in parent positive affect or decreases in negative affect preto post-writing. Due to uneven group sizes we performed two (positive affect, negative affect) Mann-Whitney $U$ tests on the change in parent PANAS scores pre- to post-writing. The alpha value for all tests was set at $\alpha=0.05$. Group medians $(M d n)$ and interquartile ranges (Iqr) are reported in text but all graphs plot means and standard errors.

\section{Results}

\subsection{Themes in parents' written responses}

Table 2 shows the two major themes, representing negative and positive affective experiences described in parents' written reports, and the 12 embedded sub-themes which constitute them. 
Table 1

Sociodemographic characteristics and objective COVID-19 experiences.

\begin{tabular}{|c|c|c|}
\hline Characteristic & \multicolumn{2}{|l|}{ Descriptive } \\
\hline Child age (years) & \multicolumn{2}{|c|}{ Mean $=10.56, S D=3.3$, range $=6-16$} \\
\hline Child sex & \multicolumn{2}{|c|}{ Male $48.8 \%$, Female $48.8 \%$, no response $2.4 \%$} \\
\hline Child race and ethnicity & \multicolumn{2}{|c|}{ White (non-Hispanic) $44.2 \%$, Multi-racial $14 \%$, Hispanic $9.3 \%$, Asian-American $2.3 \%$, no response $30 \%$} \\
\hline $\begin{array}{l}\text { Parent relation to the children } \\
\text { in the study }\end{array}$ & \multicolumn{2}{|c|}{ Biological mother $89 \%$, Biological father $5.5 \%$, Adoptive mother $5.5 \%$} \\
\hline Parent race and ethnicity & \multicolumn{2}{|c|}{ White (non-Hispanic) $73.2 \%$, Hispanic $8.92 \%$, Asian American $8.92 \%$, African American 3.6\%, no response $1.8 \%$} \\
\hline Parental education & \multicolumn{2}{|c|}{$\begin{array}{l}\text { Elementary school } 1.8 \% \text {, high school } 3.6 \% \text {, vocational/technical school } 3.6 \% \text {, some college } 5.4 \% \text {, bachelor's degree } 32.1 \% \text {, } \\
\text { master's degree } 28.6 \% \text {, professional degree } 5.4 \% \text {, doctoral degree } 19.6 \%\end{array}$} \\
\hline $\begin{array}{l}\text { Parent worker status during } \\
\text { COVID-19 }\end{array}$ & \multicolumn{2}{|c|}{ Non-essential worker $86 \%$, essential worker $7 \%$, no response $7 \%$} \\
\hline $\begin{array}{l}\text { Parent-reported subjective } \\
\text { social status* }\end{array}$ & \multicolumn{2}{|c|}{ Mean $=7.22, S D=1.18$, range $=4-9($ possible range $=1-10)$} \\
\hline Parent-reported income & Primary caregiver & Secondary caregiver \\
\hline (USD) & $25 \%$ & $1.9 \%$ \\
\hline$<\$ 17,000$ & $1.8 \%$ & $3.6 \%$ \\
\hline$\$ 18,000-\$ 24,999$ & $10.7 \%$ & $7.1 \%$ \\
\hline$\$ 25,000-\$ 49,999$ & $35.7 \%$ & $26.8 \%$ \\
\hline$\$ 50,000-\$ 99,999$ & $8.9 \%$ & $17.9 \%$ \\
\hline$\$ 100,000-\$ 149,999$ & $12.5 \%$ & $32.1 \%$ \\
\hline \multicolumn{3}{|l|}{$\$ 150,000$ or more } \\
\hline Geographic location & \multicolumn{2}{|c|}{ Urban $32 \%$, suburban $62.5 \%$, rural $5.4 \%$} \\
\hline Country representation & \multicolumn{2}{|c|}{ United States of America $85.7 \%$, Australia $8.9 \%$, Qatar 3.6\%, Georgia $1.8 \%$} \\
\hline COVID-19 illness & \multicolumn{2}{|c|}{$\begin{array}{l}\text { Parent knew no one with COVID-19 } 58.9 \% \text {, themselves or a family member/close friend were ill } 30.4 \% \text {, both themselves } \\
\text { and a family member/close friend were ill } 10.7 \%\end{array}$} \\
\hline COVID-19 known deaths & \multicolumn{2}{|c|}{ Parent knew someone who had passed away due to COVID-19 $17.9 \%$} \\
\hline COVID-19 impact $^{\dagger}$ & \multicolumn{2}{|c|}{ Mean $=7.34, S D=1.98$, range $4-13($ possible range $=4-17)$} \\
\hline
\end{tabular}

* Subjective social status was reported using the MacArthur Scale of Subjective Social Status visual ladder (Adler et al., 2000).

$\uparrow$ Higher scores represent worse COVID-19 impact

\subsection{Negative themes}

Concerns about the impact of COVID-19 on children's lives. Many parents (24 of 56) expressed empathy and concern about how COVID-19 was impacting their children's lives. Concerns focused on education, missed opportunities, and children's mental health (e.g., ID56 "My oldest daughter has started having panic attacks about dying every night").

Concerns about health. Many parents (21/56) expressed health concerns about elderly parents, family members, or friends. Personal health concerns $(9 / 56)$ tended to surround pre-existing health conditions (e.g., ID56 "I'm so scared that I'll get sick and be in the hospital again. I've had surgery on my chest in the past year and I've had pneumonia twice."). Several parents $(4 / 56)$ had low health concerns because they were "being extremely careful', or because of decreasing cases.

A stressful balancing act. About one-third of parents (20/56) wrote about the stressors and increased demands they faced during COVID19 , including the balancing act between working, parenting and schooling their children from home. Parents disclosed feeling 'stretched thin', worrying their children weren't getting enough attention, feeling overwhelmed with responsibilities, and being emotionally and physically drained (e.g., ID28 "Day-to-day household duties and chores have become even more burdensome due to lack of time to manage outside of schoolwork, working full-time remotely, checking in on loved ones, and finding alternative ways for our children to remain social."). Several parents mentioned higher relational and living condition stressors, and exacerbations to pre-existing stressors. Some parents expressed hopelessness (e.g., ID35 "Just giving up would be so much easier. Since the kids are not learning anything anyway, why bother?")

Yearning for normalcy. Some parents $(16 / 56)$ yearned for things to go back to 'normal', including spending more in-person time with friends and family, being outdoors and in nature, and engaging in daily acts to make life feel more 'normal'.

Fears about the future. Several parents (14/56) worried about an uncertain future, including running out of supplies, job insecurity, instability of the world economy, and the future of social interactions (e.g.,
ID08 "My daughter fell off her bike this week and fractured her elbow. No one stopped to help. Is this going to be the new normal?").

Anger and frustration. Parents (9/56) expressed anger and frustration towards landlords, schools, teachers, family members, and day-to-day inconveniences brought about by COVID-19 (e.g., ID36 "This time has been confusing, frustrating, irritating and difficult in terms of attempting to manage my job at home as well as have children in the home.").

Political dissatisfaction. Nine parents wrote about their political grievances, including a loss of faith in government, criticisms of pandemic policies (or lack thereof), and politicization of the pandemic (e.g., ID35 "It is a scary time. No one can agree what is the right thing to do. Politicians seem more focused on how to get power and support than on what is best for people.").

Hard truths and lessons learned. Some parents $(8 / 56)$ reflected on realizations they had come to during the pandemic, such as their parenting abilities, and marital difficulties (e.g., ID40 "My husband does not help very much, complains a lot and loses his temper with my kids. It is pretty awful. I thought we might get a divorce at one point because of the way he was treating the kids.").

Guilt. A few parents (4/56) expressed guilt about their own privilege, the uneven impact of the virus in the community, and about not 'doing more' to help out (e.g., ID12 "I see what a lot of my family and friends are doing to help the community and that's all I really want to be doing, but I do not have one ounce of energy to do so, so there is sadness in that and guilt.").

\subsection{Positive themes}

Perspective taking and gratitude. Many parents (20/56) expressed gratitude for living in an economically developed nation, financial security, their health, supportive relationships, childcare, faith, and for what COVID-19 had brought to their family, including more time together (e.g., ID14 "This has been a very positive experience for our family, as we're very lucky to have outdoor space and enough funds to get through 
Table 2

Parent reported qualitative themes.

\begin{tabular}{|c|c|c|}
\hline PARTICIPANT ID & THEMES & EXEMPLAR QUOTES \\
\hline \multicolumn{3}{|c|}{ Negative affective themes } \\
\hline 03 & $\begin{array}{l}\text { Concerns about } \\
\text { children }\end{array}$ & $\begin{array}{l}\text { "I worry my son with special needs will fall further behind and struggle more. His } \\
\text { class has been slow to start online classes, as in none for the first month. His } \\
\text { outside services which he'd been receiving three times a week abruptly stopped and } \\
\text { he had been making progress." }\end{array}$ \\
\hline 31 & Concerns about health & $\begin{array}{l}\text { "Covid doesn't really scare me a lot. I feel like if I stay home except for essentials, } \\
\text { and use caution I will be okay." }\end{array}$ \\
\hline 56 & $\begin{array}{l}\text { A stressful balancing } \\
\text { act }\end{array}$ & $\begin{array}{l}\text { "My husband's job is essential and he's working constantly, so it's on me to take } \\
\text { care of the house, the kids and my job. It's too much to do. There's just not enough } \\
\text { time in the day. There's too much that I'm worrying about. I'm exhausted and feel } \\
\text { like I can't get enough sleep" }\end{array}$ \\
\hline 45 & Yearning for normalcy & "I'm ready for this to be over. Ready for some normalcy." \\
\hline 17 & Fears about the future & $\begin{array}{l}\text { "I do not know what happens next, It's scary. I try not to think too far into the } \\
\text { future or I get really upset. I try to be present and remember that I can only control } \\
\text { myself." }\end{array}$ \\
\hline 01 & Anger and frustration & $\begin{array}{l}\text { "I am saddened by people in my community who do not comply or show concern } \\
\text { for each other. Many people in my apartment building refuse to wear a mask or } \\
\text { social distance when they are walking in the common areas. I have seen neighbors } \\
\text { congregate without masks and they are closer than } 6 \mathrm{ft} \text { " }\end{array}$ \\
\hline 14 & Political dissatisfaction & $\begin{array}{l}\text { "The stress I hold about this situation is more about the political sphere and how } \\
\text { divided we are as a country - even with this common enemy. It worries me that this } \\
\text { situation - and ultimately people's lives - will be used as political pawns to win } \\
\text { elections, rather than doing what's right for people" }\end{array}$ \\
\hline 55 & $\begin{array}{l}\text { Hard truths and } \\
\text { lessons learned }\end{array}$ & $\begin{array}{l}\text { "For me, personally, the thought of being home with my kids full-time would bring } \\
\text { about so many feelings of angst. I have always had difficulty with being still and } \\
\text { present when it comes to my kids. Being at home and having so much time with } \\
\text { them with little distraction was the ultimate test for me. I learned a lot about } \\
\text { myself during this time and am happy to report that I pushed through to the other } \\
\text { side where I am no longer anxious to simply "be" with my kids." }\end{array}$ \\
\hline 02 & Guilt & $\begin{array}{l}\text { "... as I sit largely inoculated from it all, the weight of the guilt feels so very heavy } \\
\ldots \text { as we sit in our comfortable white upper middle class bubble that there's literally } \\
\text { no escape from right now." }\end{array}$ \\
\hline \multicolumn{3}{|c|}{ Positive affective themes } \\
\hline 21 & $\begin{array}{l}\text { Perspective taking and } \\
\text { gratitude }\end{array}$ & $\begin{array}{l}\text { "The silver lining to Covid- } 19 \text { for me has been that I have been forced to slow down. } \\
\text { No longer running around to numerous activities each week for my children has } \\
\text { allowed me to spend quality time with them. We have done things we never had } \\
\text { time to do before...". }\end{array}$ \\
\hline 31 & Unexpected upsides & $\begin{array}{l}\text { "...my husband works in Chicago during the work week and is normally only home } \\
\text { on weekends or holidays. The stay-at-home order has meant that this is the first } \\
\text { time in over } 7 \text { years that we have been together constantly. It has been wonderful!" }\end{array}$ \\
\hline 18 & Learning to adjust & $\begin{array}{l}\text { "My children are learning resilience, character building, prioritizing, schedule } \\
\text { planning and other life lessons ..." }\end{array}$ \\
\hline
\end{tabular}

this... It's been a time we've been in service to each other and relied on each other in a far deeper way.").

Unexpected upsides. Several parents (16/56) mentioned unexpected upsides of the pandemic, including no work commute and improved partner relationships. Some also expressed pride in their children's capacity to manage the challenging situation well (e.g., ID16 “...proud mostly of how my family and especially my children have responded and adapted to the situation.").

Learning to adjust. Several parents (13/56) described the process of adjustment within their family (e.g., ID24 "I became better at scheduling and felt much better about helping our kids do their therapies and classes online and providing enrichment at home.").

\subsection{Themes in children's written responses}

Table 3 shows the two major themes, representing negative and positive affective experiences, and the nine embedded sub-themes in children's written reports.

\subsubsection{Negative themes}

Missing school and social connections. Most children (25 of 43) reflected on the impact the pandemic was having on their school social life (e.g., IDC08 "I have hated not seeing my friends and not going to school...."). While six children described the insufficiencies of virtually- mediated social connection (e.g., IDC12 "I miss my friends. Texting and FaceTime aren't the same as seeing someone physically and joking around with them."), a few children (4/43) expressed the opposite sentiment (e.g., IDC48 "It makes it better that I can FaceTime them or Zoom them, so that's fun!").

Fears and difficulties. Children (19/43) reported a range of challenges related to COVID-19. Two children expressed mental health struggles (e.g., IDC30 “... I am in one of the worst mental states I've ever been in. I have been diagnosed with depression, ADHD, and anxiety and the events unraveling around [me] have made those negative thoughts come to the front of my mind."). Three described not feeling afraid of COVID19, and two children explicitly expressed needing their parents to keep them safe and reassure them during this time.

Mixed feelings about learning from home. Distinct from reflections about school social life, many children (18/43) shared their experiences engaging in school from home. While many children expressed exhaustion, low motivation, dissatisfaction, and learning challenges online, they also enjoyed some aspects of not going to school (e.g., IDC10 "School has been hard and not interesting. I really miss my friends, but it's been good being at home with my dog and family".).

Missing out. Children (17/43) missed their extracurricular activities (e.g., sports, girl scouts), and 'normal' everyday events, like going to public places. Several children reported feeling regret or sadness at having missed out on (or expecting to miss out on) milestone events, like 
Table 3

Child reported qualitative themes.

\begin{tabular}{|c|c|c|}
\hline PARTICIPANT ID & THEMES & EXEMPLAR QUOTES \\
\hline \multicolumn{3}{|c|}{ Negative affective themes } \\
\hline C48 & $\begin{array}{l}\text { Missing school and social } \\
\text { connections }\end{array}$ & $\begin{array}{l}\text { "It [COVID-19] does put a strain on friendships because a lot of the } \\
\text { friendship was built on seeing them [friends] and being in classes together." }\end{array}$ \\
\hline C42 & Fears and difficulties & $\begin{array}{l}\text { "We wore masks yesterday to pick up lunch at my favorite lunch place that I } \\
\text { haven't eaten at in like } 6 \text { weeks. I wore a mask and this guy was talking } \\
\text { with my momma and kind of got close to me and I got a little scared to get } \\
\text { the virus. I hated that - it freaked me out a lot." }\end{array}$ \\
\hline C11 & $\begin{array}{l}\text { Mixed feelings about learning } \\
\text { from home }\end{array}$ & $\begin{array}{l}\text { "Learning from home is exhausting and my entire family is on a screen all } \\
\text { day trying to get things done. We all hate it but have no alternative if we } \\
\text { want to keep our grades up/keep our jobs." }\end{array}$ \\
\hline C38 & Missing out & $\begin{array}{l}\text { "It's affected us because we can't go anywhere and go to fun places. We } \\
\text { can't see our family because of COVID- } 19 \text {. We mostly have to stay indoors, } \\
\text { we can't go anywhere fun, we can't go swimming and we have to stay in the } \\
\text { car when we go shopping." }\end{array}$ \\
\hline $\mathrm{C} 17$ & Family concerns & "I'm a little scared of my family getting sick. If they get sick I will call 911." \\
\hline $\mathrm{C} 09$ & Family tensions & $\begin{array}{l}\text { "... while I know that this will end up being a good thing, it isn't going so } \\
\text { great right now. I think we are all feeling all the pressure of this situation } \\
\text { and are starting to go a little crazy. We aren't used to being in the house all } \\
\text { together for the whole day and that has led to some frustration. We have } \\
\text { plenty of fights and mishaps as we try and get through this tough time. We } \\
\text { are all trying to push through it and despite all the frustration..." }\end{array}$ \\
\hline $\mathrm{C} 12$ & $\begin{array}{l}\text { Broader consequences and } \\
\text { societal impact }\end{array}$ & $\begin{array}{l}\text { "I think COVID-19 brought us time to reflect on how small we are and how } \\
\text { we do not control everything. It's disheartening to see so many people } \\
\text { taking advantage of COVID to cause pain and confusion to people who are } \\
\text { trying so hard to make a living. Why can't we just bond as a human race } \\
\text { and fight this problem together? Why do people have to go out and break } \\
\text { quarantine? Ironically these people are the people who are complaining } \\
\text { about how long we're stuck at home but they are the ones imposing this } \\
\text { punishment upon themselves going out." }\end{array}$ \\
\hline \multicolumn{3}{|c|}{ Positive affective themes } \\
\hline $\mathrm{C} 05$ & Unexpected upsides & “... at least I get to ride bikes and go in the pool." \\
\hline $\mathrm{C} 09$ & Closer family bonds & $\begin{array}{l}\text { "I think it will bring us together as a family. I mean, nothing quite like this } \\
\text { has ever happened and at least I am living it with the people I love most. I } \\
\text { know we will get through this time and be closer than ever. We are learning } \\
\text { things about each other and finding new things to do. We may fight and } \\
\text { whine, but we love each other through thick and thin. We are growing } \\
\text { during this time, both individually and as a family. It may be a bad time, but } \\
\text { we will pull through and have the strongest bond we could ever imagine." }\end{array}$ \\
\hline
\end{tabular}

birthday celebrations and graduations (e.g., IDC41 "I might not be able to have a bigger birthday party because we can't have that many people".).

Family concerns. Some children (9/43) expressed concerns about their family, including fears about the direct and indirect impacts of COVID-19 on family members, and sadness at not being able to see some relatives (e.g., IDC37 "The hardest part is not getting to see grandparents and cousins. I cry when I talk to people on the phone or video because I miss being able to hug them.").

Family tensions. Some children (7/43) described tensions within their family during lockdown (e.g., IDC11 "Being together constantly has only made us more aware of all things that annoy us about each other.").

Broader consequences and societal impact. A small subset of children (4/43) who tended to be older (see Fig. 1), had deeper reflections about the potential consequences of COVID-19 for society, politics, and the future of the human race (e.g., IDC16 "I am worried that half of the planet will be dead after [COVID-19] ends.").

\subsubsection{Positive themes}

Unexpected upsides. Almost one-quarter of children (10/43) wrote about unexpected upsides to the pandemic, including more time for engaging in pleasurable activities (e.g., yoga, video games, painting), and mastering new skills (e.g., IDC40 "I learned to ride a bike and I am very happy about that...").

Closer family bonds. Six children described developing closer family bonds during COVID-19, due to the increased time spent together (e.g., IDC09 "Through all the fighting and all the frustration, we pull together as a family and stick through this crisis".).

\subsection{Effect of reflective writing exercise on parent affect}

There was no difference in the distribution of change in positive affect pre- to post-writing based on thematic content $\left(M d n_{\text {gratitude cited }}=0\right.$, $I q r$ gratitude cited $=4$, vs. $M d n$ gratitude not cited $=0, I q r$ gratitude not cited $=3.5$; $W=289, p=0.779$ ); however, the distribution of change in negative affect pre- to post-writing based on thematic content was not equal between groups ( $M d n_{\text {gratitude cited }}=0, I q r_{\text {gratitude cited }}=1$, vs. $M d n$ gratitude not cited $=0$, Iqr gratitude not cited $=3.5 ; W=438.5, p=0.027$ ). Parents who cited gratitude in their written responses reported an average decrease in negative affect pre- to post-writing, while those who did not cite gratitude reported an average increase in negative affect pre- to post-writing (Fig. 2).

\section{Discussion}

Parents and children in this study reflected on both negative and positive affective experiences in their written responses about the impact of COVID-19. For parents, negative affective themes included expected domains such as fears associated with COVID-19 (concerns about health) and parenting stress (stressful balancing act). These domains have been reported in research on COVID-19 using mostly quantitative measures (Saurabh and Ranjan, 2020; Cameron et al., 2020; Whittle et al., 2020). We also identified new negative themes in parent reports, most of which were externally focused (e.g., concerns about their children and others, worry about the state of the world, politics and the global economy). While positive parent themes also covered expected domains perspective taking and gratitude (Sun et al., 2020) - we identified two new 


\begin{tabular}{|ll|}
\hline $\begin{array}{l}\text { Child } \\
\text { Age }\end{array}$ & $\boldsymbol{N}$ \\
\hline 6 & 4 \\
7 & 7 \\
8 & 4 \\
9 & 4 \\
10 & 3 \\
11 & 4 \\
12 & 4 \\
13 & 3 \\
14 & 2 \\
15 & 4 \\
16 & 4 \\
\hline
\end{tabular}

\section{Thematic Content In Child Written Reports}

Broader consequences and societal impacts

Positive affective content

Negative affective content

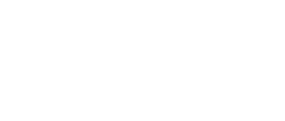

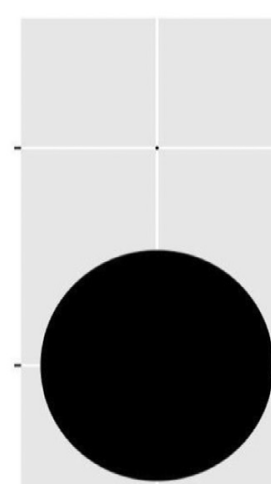
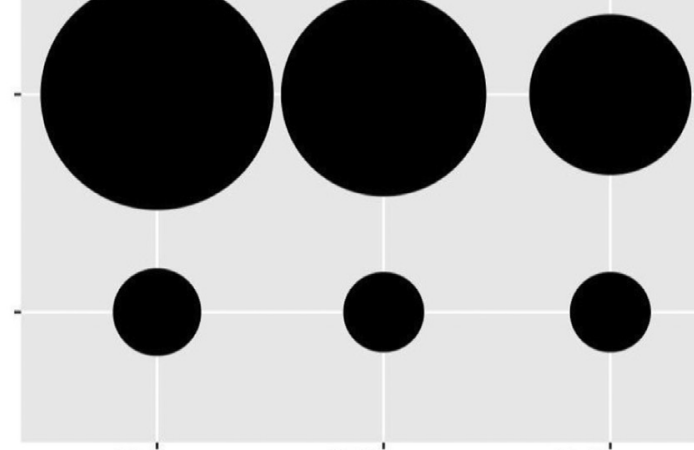

6-9 y'ears
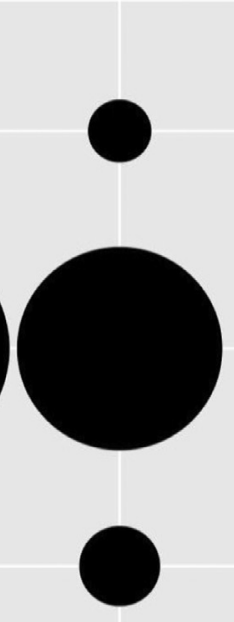

10-13'years Age Group
Number of children citing the theme

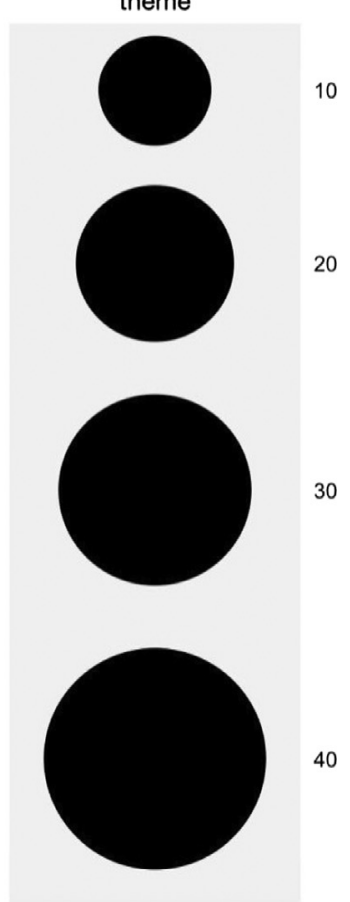

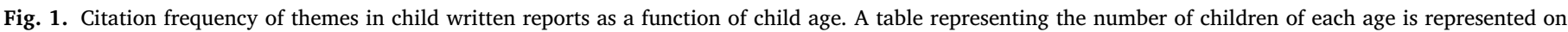

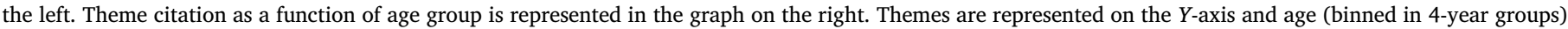

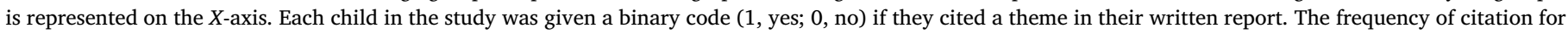
each age group is indicated by the size of the bubble, with larger bubbles indicating a higher frequency of citation in the group.

\section{Parent Affect Change During Reflective Writing As a Function of Content}

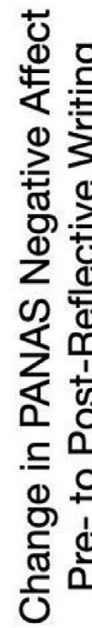

$$
\begin{array}{r|}
3 \\
2.5 \\
2 \\
1.5 \\
1 \\
0.5 \\
0 \\
-0.5 \\
-1 \\
-1.5 \\
-2
\end{array}
$$
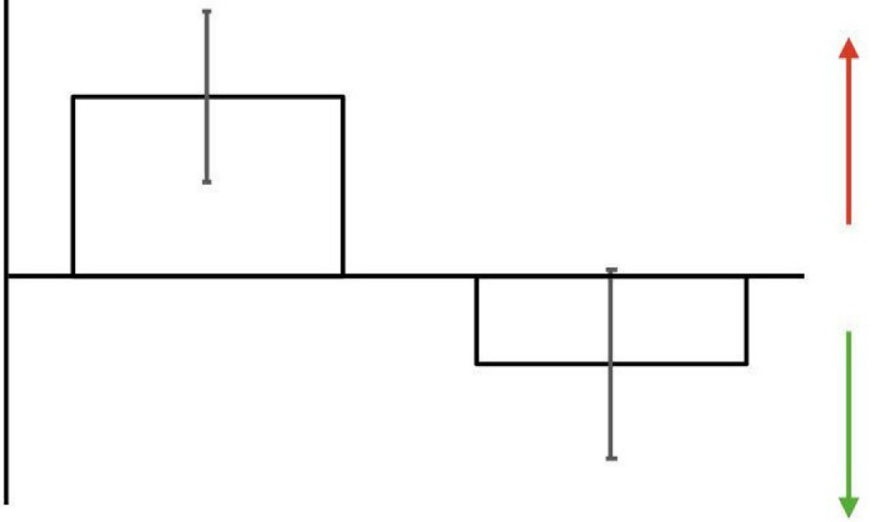

Increase in negative affect

Did not Cite Gratitude Theme in Reflective Writing
Cited Gratitude Theme in Reflective Writing

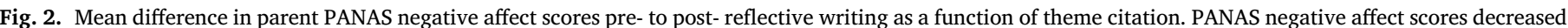

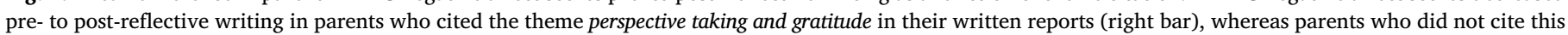

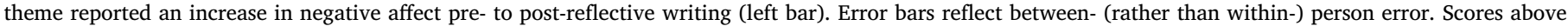

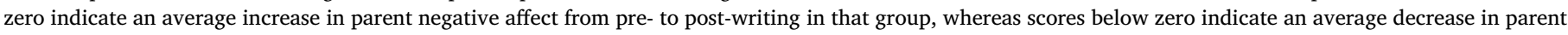

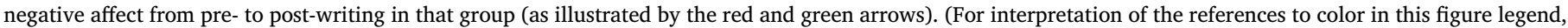
the reader is referred to the web version of this article.) 
positive themes - unexpected upsides, and learning to adjust. Moreover, we observed that the process of writing about COVID-19 was an active emotional experience for parents, with those who reflected on positive themes (i.e., perspective taking and gratitude) during writing also reporting a decrease in negative affect at the conclusion of writing. The variety of both positive and negative themes in parents' writing demonstrates the multifaceted nature of responses to this pandemic and highlights that, even in the face of the extreme burdens posed by COVID-19, at least some parents were abstracting greater meaning from their experiences.

In terms of children's written responses, we also observed affective content that covered expected theoretical domains of fear reactions to COVID-19 (fears and difficulties), and identified several non-theorized negative themes. In contrast to the negative themes that were typical of parent's written reports, children's negative affective concerns were mostly egocentric, with the most commonly expressed concerns relating to the impact of the virus on their school social life. As seen in Fig. 1, citation of any negative affective theme was much more frequent in younger children (6-9 years) than in the older children (14-16 years), perhaps reflecting the negativity bias known to exist in youth (Hamlin et al., 2010; Tottenham et al., 2013). Interestingly, the theme 'broader consequences and societal impacts' was only expressed by children aged 10-13 years and 14-16 years, suggesting that the egocentric focus was lessening as children matured, which is in line with developmental expectations (Riva et al., 2016; Epley et al., 2004). While we did not find high citations or strong endorsement of positive themes in children's written reports, at least some children mentioned positives such as learning new skills, whereas others were able to take a more familial perspective, reflecting on the closer family bonds that had developed during this time. Thus, it is clear that although COVID-19 is having a significant multifaceted impact on families, the precise way this event is interpreted and experienced differs for parents and their children, and across the developmental spectrum.

Considering parent and child responses in concert, the results of this study suggest that the closure of in-person schooling has been a particularly strong driver of both parent and child distress. One of the greatest burdens described by parents and children in this study centered on the impact of schooling from home. Parents were concerned about their children's missed academic opportunities and were struggling to motivate their children to engage in online classes, while often simultaneously working from home themselves. Children in the sample were most concerned with the loss of social contact afforded by in-person schooling and some children described struggling to learn in the online environment. Contrary to research supporting the quality of online relationships (Parks and Roberts, 1998), six children specifically mentioned the inadequacies of digital technologies for filling the social gap created by school closures. While some researchers have suggested that digital technologies may help to bridge social distance during the pandemic (Galea et al., 2020), the data from this study suggests that online relationships complement, but do not a substitute in-person social interactions amongst youth. While schools reopening across the globe have met with varying levels of success (Viner et al., 2020; Stein-Zamir et al., 2020; PanovskaGriffiths et al., 2020), it is clear that sustained attention and resources dedicated to establishing evidence-based strategies for safe and sustainable school reopening could go a long way in supporting the health and wellbeing of both children and parents.

Another area that might be constructive in improving parent adjustment and wellbeing is to focus on perspective taking and gratitude. Parents who wrote about their gratitude also reported a decrease in negative affect pre- to post-writing, relative to parents who did not reflect on this topic. Reflecting on gratitude has been successfully used as a psychotherapeutic intervention to improve wellbeing and reduce stress (Bohlmeijer et al., 2021). A study during COVID-19 showed that daily reflections on gratitude increased employees' work satisfaction (Butler and Jaffe, 2020), while another study involving college students found pre-COVID-19 levels of expressed gratitude were predictive of a reduced negative impact of the pandemic on student academic performance (Bono et al., 2020). While no amount of gratitude will undo the systemic inequities highlighted and intensified by the COVID-19 pandemic, the practice may have at least a temporary positive impact on parent emotional wellbeing and should be examined as a potential intervention with efficacy for some families.

\subsection{Study limitations}

Study findings should be interpreted in light of several limitations. The sample included a cross-section of mostly White (non-Hispanic), dual income, well-educated mothers, primarily from the United States, and data were collected during a specific period relatively early in the pandemic (April-May 2020). Thus, it is possible the findings may not generalize outside of the specific demographics, time period, and geographic locations represented by this sample. Also, given the writing prompt occurred at the end of a survey which included quantitative measures on anxiety, parenting stress, and COVID-19 impact, it is possible that parents may have been primed to write more on those topics.

\section{Conclusions}

While both parents and children are gaining some perspective from this pandemic, the overwhelming subjective experience spontaneously generated in written reports was negative. Clear from these reports is the significant psychosocial toll of COVID-19 for individuals as well as families as a whole. Considering the relatively advantaged sample studied, we predict the psychosocial toll of the pandemic would be even greater in magnitude within less advantaged populations. Future research and policy should focus on identifying how to fulfill children's social needs and lessen parents' caregiving burdens during this time.

\section{Contributors}

The authors would like to thank Danielle Ladensack, Aileen Gozali, Daisy Ramirez, Grant Grech, Nicole Fonacier and Reese Wix for their assistance in the study set up and recruitment.

\section{Funding}

This research did not receive any specific grant from funding agencies in the public, commercial, or not-for-profit sectors.

\section{Declaration of Competing Interest}

None

\section{Acknowledgments}

Nadine Kasparian is the recipient of a National Heart Foundation of Australia Future Leader Fellowship (101229).

\section{References}

World Health Organization. World Health Organization: coronavirus disease dashboard https://covid19.who.int/(2020).

Luo, M., Guo, L., Yu, M., Jiang, W., Wang, H., 2020. The psychological and mental impact of coronavirus disease 2019 (COVID-19) on medical staff and general public - a systematic review and meta-analysis. Psychiatry Res. 291, 113190.

Prime, H., Wade, M., Browne, D.T., 2020. Risk and resilience in family well-being during the COVID-19 pandemic. Am. Psychol. 75, 631-643.

Golberstein, E., Wen, H., Miller, B.F.C D 2019, 2020. COVID-19) and mental health for children and adolescents. JAMA Pediatr. doi:10.1001/jamapediatrics.2020.1456.

Bhamani, S., et al., 2020. Home learning in times of COVID: experiences of parents. J. Educ. Educ. Dev. 7, 9-26.

Van Lancker, W., Parolin, Z., 2020. COVID-19, school closures, and child poverty: a social crisis in the making. Lancet Public Health 5, e243-e244.

Duan, L., et al., 2020. An investigation of mental health status of children and adolescents in china during the outbreak of COVID-19. J. Affect. Disord. 275, 112-118. 
Saurabh, K., Ranjan, S., 2020. Compliance and psychological impact of quarantine in children and adolescents due to Covid-19 pandemic. Indian J. Pediatr. 87, 532-536.

Racine, N., Cooke, J.L., Eirich, R., Korczak, D.J., McArthur, B., Madigan, S., 2020. Child and adolescent mental illness during COVID-19: a rapid review. Psychiatry research, 292, 113307. Advance online publication. Psychiatry Res..

Bobo, E., et al., 2020. [How do children and adolescents with Attention deficit hyperactivity disorder (ADHD) experience lockdown during the COVID-19 outbreak?]. Encephale 46, S85-S92.

Gunnar, M.R., Hostinar, C.E., 2015. The social buffering of the hypothalamic-pituitary-adrenocortical axis in humans: developmental and experiential determinants. Soc. Neurosci. 10, 479-488.

Cluver, L., et al., 2020. Parenting in a time of COVID-19. Lancet 395, e64.

Jenco, M.S, 2020. COVID-19 pandemic exacerbated hardships for low-income, minority families. AAP News. https://www.aappublications.org/news/2020/06/03/covid19 hardships060320.

Cameron, E.E., et al., 2020. Maternal psychological distress \& mental health service use during the COVID-19 pandemic. J. Affect. Disord. 276, 765-774.

Thapa, S.B., Mainali, A., Schwank, S.E., Acharya, G., 2020. Maternal mental health in the time of the COVID-19 pandemic. Acta Obstet. Gynecol. Scand. 99, 817-818.

Brown, S.M., Doom, J.R., Lechuga-Peña, S., Watamura, S.E., Koppels, T., 2020. Stress and parenting during the global COVID-19 pandemic. Child Abuse Negl. doi:10.1016/j.chiabu.2020.104699.

Günther-Bel, C., Vilaregut, A., Carratala, E., Torras-Garat, S., Pérez-Testor, C., 2020. A mixed-method study of individual, couple and parental functioning during the stateregulated COVID-19 lockdown in Spain. Fam. Process doi:10.1111/famp.12585.

Pennebaker, J.W., 1997. Writing about emotional experiences as a therapeutic process. Psychol. Sci. 8, 162-166.

Murray, E.J., Segal, D.L., 1994. Emotional processing in vocal and written expression of feelings about traumatic experiences. J. Trauma. Stress 7, 391-405.

Pennebaker, J.W., Francis, M.E.C, 1996. Emotional, and language processes in disclosure. Cognit. Emot. 10, 601-626.

Toepfer, S., Walker, K., 2009. Letters of gratitude: improving well-being through expressive writing. J. Writ. Res. 1, 181-198.

Booker, J.A., Dunsmore, J.C., 2017. Expressive writing and well-being during the transition to college: comparison of emotion-disclosing and gratitude-focused writing. J. Soc. Clin. Psychol. 36, 580-606.

Braun, V., Clarke, V., 2006. Using thematic analysis in psychology. Null 3, 77-101.

Watson, D., Clark, L.A., Tellegen, A., 1988. Development and validation of brief measures of positive and negative affect: the PANAS scales. J. Pers. Soc. Psychol. 54, 1063-1070.

Whittle, S., Bray, K. O., Lin, S. \& Schwartz, O. Parenting and child and adolescent mental health during the COVID-19 pandemic. (2020) doi:10.31234/osf.io/ag2r7.
Sun, N., et al., 2020. A qualitative study on the psychological experience of caregivers of COVID-19 patients. Am. J. Infect. Control 48, 592-598.

Hamlin, J.K., Kiley Hamlin, J., Wynn, K., Bloom, P, 2010. Three-month-olds show a negativity bias in their social evaluations. Dev. Sci. 13, 923-929.

Tottenham, N., Phuong, J., Flannery, J., Gabard-Durnam, L., Goff, B., 2013. A negativity bias for ambiguous facial-expression valence during childhood: converging evidence from behavior and facial corrugator muscle responses. Emotion 13, 92-103.

Riva, F., Triscoli, C., Lamm, C., Carnaghi, A., Silani, G., 2016. Emotional egocentricity bias across the life-span. Front. Aging Neurosci. 8, 74.

Epley, N., Morewedge, C.K., Keysar, B., 2004. Perspective taking in children and adults: equivalent egocentrism but differential correction. J. Exp. Soc. Psychol. 40, 760-768.

Parks, M.R., Roberts, L.D., 1998. 'Making Moosic': the development of personal relationships on line and a comparison to their off-line counterparts. J. Soc. Pers. Relat. 15, 517-537.

Galea, S., Merchant, R.M., Lurie, N., 2020. The mental health consequences of COVID-19 and physical distancing: the need for prevention and early intervention. JAMA Intern. Med. 180, 817-818.

Viner, R.M., et al., 2020. School closure and management practices during coronavirus outbreaks including COVID-19: a rapid systematic review. Lancet Child Adolesc. Health 4, 397-404.

Stein-Zamir, C., Abramson, N., Shoob, H., Libal, E., Bitan, M., Cardash, T., ... Miskin, I., 2020. A large COVID-19 outbreak in a high school 10 days after schools' reopening, Israel, May 2020. Euro Surveill. 25 (29), 2001352.

Panovska-Griffiths, J., Kerr, C.C., Stuart, R.M., Mistry, D., Klein, D.J., Viner, R.M., Bonell, C., 2020. Determining the optimal strategy for reopening schools, the impact of test and trace interventions, and the risk of occurrence of a second COVID-19 epidemic wave in the UK: a modeling study. Lancet Child Adolesc. Health 4 (11), 817-827.

Bohlmeijer, E.T., Kraiss, J.T., Watkins, P., Schotanus-Dijkstra, M., 2021. Promoting gratitude as a resource for sustainable mental health: results of a 3-armed randomized controlled trial up to 6 months follow-up. J. Happiness Stud. 22 (3), 1011-1032.

Butler, J. L. \& Jaffe, S. Challenges and gratitude: a diary study of software engineers working from home during covid-19 pandemic. (2020).

Bono, G., Reil, K., Hescox, J., 2020. Stress and wellbeing in urban college students in the US during the COVID-19 pandemic: Can grit and gratitude help? IJW 10 (3).

Adler, N.E., Epel, E.S., Castellazzo, G., Ickovics, J.R., 2000. Relationship of subjective and objective social status with psychological and physiological functioning: preliminary data in healthy, White women. Health Psychol. 19, 586-592. 